\title{
Configurações
}

Revista Ciências Sociais

22 | 2018

Arte política e social: discursos e práticas

\section{El lugar del arte en las acciones políticas feministas}

The place of Art in feminist political actions

La place de l'art dans les actions politiques féministes

\section{Ana María Castro Sánchez}

\section{(2) OpenEdition}

\section{Journals}

Edição electrónica

URL: http://journals.openedition.org/configuracoes/6268

DOI: $10.4000 /$ configuracoes. 6268

ISSN: 2182-7419

\section{Editora}

Centro de Investigação em Ciências Sociais

Edição impressa

Paginação: 11-30

ISSN: 1646-5075

\section{Refêrencia eletrónica}

Ana María Castro Sánchez, «El lugar del arte en las acciones políticas feministas », Configurações [Online], 22 | 2018, posto online no dia 22 dezembro 2018, consultado o 10 dezembro 2020. URL http://journals.openedition.org/configuracoes/6268; DOI : https://doi.org/10.4000/configuracoes. 6268 
Sánchez, Ana María Castro - El lugar del arte en las acciones políticas feministas. Configurações, vol. 22, 2018, pp. 11-30.

\title{
El lugar del arte en las acciones políticas feministas
}

ANA MARÍA CASTRO SÁNCHEZ*

Facultad de Ciencias Humanas y Artes de la Universidad del Tolima - Colombia

\begin{abstract}
Resumo
Tem sido diferentes os caminhos percorridos pelos movimentos sociais na intenção de consolidar transformações na política, entre estos, podemos mencionar as acções políticas que derivam de desafios que incorporaram expressões artísticas como estratégias de luta. As acções políticas artísticas feministas são uma demonstração disso; onde as teorias feministas se constituem como fontes importantes seja para o trabalho das artistas, seja para o das activistas, estreitando a relação entre o pensamento feminista e a criação artística. Este artículo procura compreender quais são actualmente estes desafios para aprofundar a relevância que teve e tem a arte na transformação das políticas feministas.
\end{abstract}

Palabras claves: acción política, feminismos, arte, movimientos sociales.

\begin{abstract}
The place of Art in feminist political actions

There have been different roads travelled by social movements in order to consolidate changes in politics, amongst which political actions that are incorporated into artistic expressions as protest strategies. The feminist artistic political actions are an example of this, where feminist theories will become important sources for the work of artists and activists, strengthening the relationship between feminist thought and artistic creation. This article seeks to understand the current protest strategies, in order to deepen the relevance that art has had and has in the transformation of feminist politics.
\end{abstract}

Keywords: political action, feminisms, art, social movements.

*Profesora del programa de Sociología de la Facultad de Ciencias Humanas y Artes de la Universidad del Tolima - Colombia. E-mail: amcastros@ut.edu.co 


\section{Résumé \\ La place de l'art dans les actions politiques féministes}

Les mouvements sociaux ont parcouru différents chemins dans leur intention de consolider les transformations politiques, parmi lesquels on peut mentionner les actions politiques qui dérivent de paris intégrant des expressions artistiques en tant que stratégie de lutte. Les actions politiques artistiques féministes en sont une démonstration, car les théories féministes constituent des sources importantes tant pour le travail des artistes que pour celui des activistes, rendant ainsi plus étroite la relation entre la pensée féministe et la création artistique. Cet article cherche à comprendre quels sont actuellement ces paris afin d'approfondir la pertinence qu'a eue et continue d'avoir l'art dans la transformation des politiques féministes.

Mots-clés: action politique, féminismes, art, mouvements sociaux.

La creatividad es un instrumento de lucha y el cambio social es un hecho creativo y la acción creativa es una acción politica. Mujeres Creando 2005, Bolivia.

\section{Introducción}

En el contexto latinoamericano, los movimientos sociales desempeñan un importante papel en la construcción de proyectos sociales democráticos, donde no solo están en disputa los parámetros de la democracia sino las propias fronteras de lo que debe ser definido como política. Estas luchas de poder implican ampliar los repertorios de la acción política y de protesta social que cuestionan la capacidad de respuesta del Estado y que, en últimas, constituyen lo que se considera un nuevo paradigma político. Han sido diversos los caminos recorridos para consolidar estas transformaciones en la política, entendiéndola de manera más amplia, al sacarla de los confines de los partidos políticos y la institucionalidad formal, una apuesta fundamental de los movimientos feministas.

En este sentido, podemos hablar hoy en día de la existencia de acciones políticas artísticas que devienen de apuestas donde los movimientos sociales incorporan expresiones artísticas como estrategias de lucha, construyendo una relación dialéctica entre sus apuestas políticas y el arte como forma de expresión de las mismas, en últimas como otra política. Se trata de una articulación con todo lo que ello implica entre prácticas artísticas, movimientos y agentes sociales, una vinculación que se hace de manera horizontal donde se condicionan mutuamente tanto el arte como la política. La acción política feminista con todas sus estrategias son una muestra de ello, donde las teorías feministas van a constituirse en fuentes importantes para el trabajo tanto de las artistas 
como de las activistas, estrechando la relación entre el pensamiento feminista y la creación artística. Este artículo busca comprender en la actualidad cuáles son esas apuestas y profundizar en particular en la relevancia que ha tenido y tiene el arte en la transformación de las acciones políticas feministas, a partir de ejemplos concretos de artistas y activistas feministas en Colombia.

\section{Miradas sobre la política}

La política ha sido un campo controvertido tanto en la teoría como en la práctica, abordado por las Ciencias Sociales desde diversas perspectivas y con énfasis que dependen del contexto histórico, social, cultural y económico. Para esta discusión me interesa comprender el paradigma que podemos denominar como tradicional, formal o institucional de la política, las críticas feministas que se han realizado al mismo y los aportes en la construcción de otra(s) política(s) y ejercicios diversos de la misma, constituidos tanto por las políticas feministas como por los movimientos sociales.

El contenido de la política que el paradigma liberal democrático formulaotorga un lugar central al Estado y sus instituciones, en el cual se enmarcan prácticas políticas reducidas a la participación convencional de la democracia representativa como expresión del ejercicio de la política. En este marco de política formal la ciudadanía va a participar en lo que se considera una democratización del Estado vía derechos políticos y civiles, que son importantes en la medida en que propician también otros espacios para la participación política tanto fuera como en relación con el Estado; como son los movimientos políticos y las diversas expresiones organizadas de la sociedad civil que van a abarcar la esfera de lo público no estatal. Así se constituyen los lugares de la política como práctica de producción y reproducción de diversos ordenes sociales y de sus propios espacios y acciones que se van a considerar en si mismas políticas y que responden a esta estructura.

La comprensión de lo político como campo que abarca distintas dimensiones además de la institucional, diferentes prácticas más allá de la participación formal, diversas acciones que generan el efecto de lo político y que deben ser consideradas como tal al reflejar posicionamientos y formas de enfrentar las relaciones de poder; permite reconocer que la política es también un espacio de disputa discursivo y simbólico que cambia de sentido y contenido. Esta es una perspectiva contraria al discurso dominante de la política y de sus actores que al ser tan hermético no permite reconocer la diversidad de expresiones de la política, así como sus protagonistas como fuerzas que la recrean constantemente afirmándose en diversas experiencias de acción política.

En este sentido, se trata de reconocer tanto la dimensión política de todas las esferas de la vida, así como el surgimiento del sentido político en relación a los cambios sobre lo que es o no político (Slater, 2000); y la necesidad de 
politizar temas, problemas, circunstancias, etc. para que salgan del espacio de la normalidad en el que muchas situaciones de exclusión, discriminación y opresión aún tienen lugar en nuestras sociedades y frente a las cuales se posicionan acciones políticas transformadoras. En esta medida, una "articulación analítica de los elementos socioculturales micro-macro nos permite analizar la acción política de los actores sociales como parte de un proceso que intenta redefinir las fronteras y transgredir las visiones reduccionistas de lo político” (Rodríguez, 2012: 265-266). Por ello, podemos entender la política como todo aquello que conforma la acción política como espacios de lucha y contrapoder, como afirman Ibarra y Cortina (2011).

Comprendida desde esta perspectiva la política empezaría a tener diversos rostros, nombres, lugares, tiempos, colores, formas, etc. que la harían visible de una manera más concreta relacionada con los contextos, estrategias, actores, poderes, territorios que la conforman y no solo como un sistema abstracto. Sin embargo, estas maneras de repensar la política y su acción no se pueden concretar si no se deconstruyen los principios en los que se basa la visión imperante de la política, uno de los cuales es la exclusión de las mujeres. Igualmente, todo ello implica la redefinición de los lugares de la política, los escenarios de su institucionalización y las acciones que se van a constituir como su ejercicio legítimo. Es aquí donde va a jugar un papel fundamental la sociedad en sus diversas expresiones organizativas que van a desestabilizar los lugares que se consideraban fijos en el ejercicio de la política. Nos encontramos entonces con alternativas, maneras de redefinir y reapropiarse, que consolidan otras formas de idear y hacer la política, que incluso se pensará en plural como otras políticas a partir de prácticas colectivas que crean nuevos significados para superar los estrechos límites de la acción política convencional.

\section{1. Los feminismos y la redefinición de la política}

Para empezar es importante aclarar que no existe una única política feminista tal como no existe un único feminismo, por lo que haré referencia de manera general a lo que diferentes políticas feministas proponen frente a la política tradicional, formal, institucional. La posición de partida será la "ruptura con la concepción clásica de la política cuya definición la reduce al ejercicio del poder público, así como con la idea de que lo político es un asunto cuyos contenidos son determinados dentro de las fronteras del sistema institucional" (Tarrés, 2002: 120).

Los movimientos feministas son reconocidos por las transformaciones que han suscitado en la concepción de la política y el ejercicio que se hacía de la misma; pensando la política de manera más amplia al reconocer que su concepción y práctica tradicional era limitante para quienes no ostentaban el poder, particularmente las mujeres a quienes les era negado por su condición y 
posición de género, así como a las personas racializadas y subalternizadas. Los feminismos vinculan la política con el ejercicio del poder en todos los ámbitos, no solo en el público, en el sentido que Mouffe (1999) señala como político al afirmar que allí donde existe una relación de poder hay una relación política que puede potenciarse o interrumpirse.

Los aportes de los feminismos a la redefinición de la política incorporan el cuestionamiento a las formas hegemónicas de ejercerla y concebirla, poniendo en discusión la supuesta racionalidad universalista y su propósito homogeneizador que desconoce la potencialidad política de las diferencias; sustentado en una generalidad y neutralidad que los feminismos han objetado ya que siempre se procede parcialmente desde posiciones que se traducen en discriminaciones y exclusiones. De esta manera, se contradice la pretensión de igualdad basada en el mencionado supuesto criterio de neutralidad y generalidad que en realidad beneficia solo a unos (Castañeda, 2002).

Asimismo, una propuesta fundamental de los feminismos para repensar la política será superar las dicotomías excluyentes sobre las que se ha sostenido la política institucional tradicional; entre ellas la diferencia entre lo público y lo privado, que implica ampliar la noción del dominio del poder público a la dominación y subordinación en el ámbito privado y sus implicaciones en la vida de las mujeres. Se cuestiona lo público concebido como lugar privilegiado de la política que se construye en contraste, negación y oposición con lo privado; lo que genera la justificación de los lugares sociales asignados a hombres y mujeres en el juego de la política formal. En este sentido, siguiendo a Nancy Fraser (1992), se trata de evidenciar las implicaciones que los términos público y privado tienen en la política, ya que no designan simplemente ámbitos sociales sino que son clasificaciones culturales y etiquetas retóricas que en el discurso político son tan poderosas que se utilizan para deslegitimar intereses, opiniones y temas, así como para valorizar otros.

Las políticas feministas van a insistir en lo que implica para el espacio del poder dominante pensar lo privado como político, sosteniendo la importancia y vigencia de la apuesta feminista de que lo personal es político. Además, los feminismos han destacando el papel que tiene la cultura patriarcal en la definición no solo de la vida cotidiana sino de las relaciones sociales, las instituciones y por tanto, de la política. Por ello, también cuestionan categorías como la de ciudadanía ya que ésta reconoce la supuesta igualdad formal de los individuos pero, tal como las nociones de libertad y consenso, realmente excluyen a las mujeres al ser el ámbito de lo público el principal escenario de lo que se considera político separándolo de la esfera privada y personal.

Los feminismos han sido gestores de nuevas formas de concebir lo político al politizar lo que no era considerado como tal: temas, problemas, espacios, modos de hacer, para que formen parte del debate cotidiano proponiendo 
un activismo que "tendría que y debería siempre darse en una multiplicidad de espacios y lugares que no suelen considerados «propiamente políticos»" (Álvarez, et. al., 2000: 30). Asimismo, no se trata de pensar en los intereses y necesidades de las mujeres solamente, ni de ampliar su representación en los espacios formales de la política institucional, sino de reconocer la diversidad de formas de participación política que constituyen las apuestas feministas más amplias articuladas con diversas demandas.

Otro aspecto importante para superar estos límites que impone la política formal tiene que ver con el reconocimiento de la diversidad de sujetos como agentes políticos más allá de las y los representantes y dirigentes. Ello se relaciona también con cómo se supone que se debe hacer política, expandiendo los espacios de participación, a lo que se le suma la diversidad que incluye hoy lo que consideramos como político. Así, lo que podemos reconocer como otras políticas no solo se posicionan frente a la tradicional y sus vacíos e incongruencias, sino además frente a las implicaciones de las formas actuales de dominación del capitalismo, el patriarcado, el colonialismo, el heterosexismo, el militarismo, y todos los sistemas de dominación que hoy en día imponen nuevos retos para la política.

\subsection{Los movimientos sociales y el redimensionamiento de la política}

Los movimientos sociales en su diversidad han sido un actor clave en el redimensionamiento de la política, sacándola de la esfera político-estatal al considerar que tanto las formas tradicionales de participación y representación como el rol del Estado se encuentra en crisis. Así se constituyen en actores políticos que toman la palabra que muchas veces les fue negada, diversificando las demandas que ya no se agotan en el reconocimiento formal de derechos que suponía la lucha política, lo que lleva a replantear conceptos claves como el de ciudadanía y a transformar la acción política.

En esta línea de reflexión, Sonia Álvarez, Evelina Dagnino y Arturo Escobar (2000) analizan como en el contexto latinoamericano los movimientos sociales desempeñan un importante papel en la construcción de proyectos sociales democráticos, donde no solo están en disputa los parámetros de la democracia y el sentido de nociones convencionales que abarca la política (ciudadanía, representación, participación, etc.), sino las “propias fronteras de lo que debe ser definido como arena política: sus participantes, instituciones, procesos, agendas y campos de acción [evidenciando una] amplia gama de esferas públicas posibles" (Álvarez et. al., 2000: 15-16); donde la ciudadanía sea ejercida en todas sus dimensiones y los intereses de la sociedad no solo sean representados sino remodelados. Así los lugares y las formas que considerábamos estables para el ejercicio de la política van a ser insuficientes frente a las propuestas de los movimientos sociales, por ello la política va a estar en 
constante construcción, transitando y politizado espacios, entre ellos los que habían sido neutralizados y despolitizados, así como asuntos que no eran considerados como políticos.

Para que esto sea posible, David Slater (2000) afirma que una característica de lo político será el cuestionamiento de lo socialmente dado, así los movimientos sociales subvierten los datos tradicionales del sistema político cuestionando su funcionamiento aparentemente normal y natural revelado los significados velados de lo político encerrado en lo social. De allí que uno de sus elementos más importantes sea las maneras como los movimientos sociales contribuyen a reconfigurar lo político en las condiciones actuales, transformando la acción política convencional como reflejo de otras formas de ejercer la ciudadanía.

Estas luchas implican además una política simbólica, en el sentido de luchas por el poder interpretativo que se desencadenan cuando entran en conflicto distintos universos simbólicos sobre lo político (Delgado, 2007). Así las nuevas maneras de pensar y ejercer la política que concretizan los movimientos sociales se identificará como una dimensión de la cultura relacionada con las luchas por los sistemas de representación (Maccioni, 2002). Es en ese sentido que podemos comprender "que los cuestionamientos culturales no son meros subproductos de las luchas sociales, sino más bien elementos constitutivos de los esfuerzos orientados hacia nuevas definiciones del significado y de los límites del propio sistema político por parte de los movimientos sociales" (Dagnino en Escobar, et. al., 2001: 27). La cultura por tanto se transforma en un hecho político (Álvarez et. al., 2000), lo que hace importante comprender en la actualidad cómo se concreta esta apuesta; una forma es profundizar particularmente en la relevancia que ha tenido y tiene el arte en la transformación de la acción política y por tanto en la redefinición de la política.

\section{La potencia política del arte}

El arte con sus propios medios tiene la capacidad de movilizar tanto individual como colectivamente, esto implica reconocer que no es un recurso sino que en sí mismo el arte contiene una potencia que logra no solo mostrar, transmitir, sino incluso incidir en transformaciones sociales. De allí la importancia de comprender su potencia política, cómo y por qué puede llegar el arte a ser útil en y para movilización política; abordando las prácticas artísticas en el sentido de cómo pueden adecuarse y articularse para convertirse en elementos de la praxis política, recurriendo a sus medios, fortaleciendo sus potencialidades. Se trata de reafirmar lo que el arte aporta, remueva, favorece, impulsa en y para los proyectos políticos, teniendo en cuenta lo que logra en términos de producción de sentidos y su carácter relacional. 
Un aspecto que posibilita repensar la experiencia artística, no como algo definido y exclusivo de un espacio, una clase, un momento histórico, es su relación con la política, comprendida como un devenir donde confluyen varios aspectos que parten de reconocer el lugar que el arte ocupa en una sociedad y la manera como contribuye a un cambio. Para Chantal Mouffe (2007) el arte y la política no se pueden separar, porque existe una dimensión estética en la política, así como existe una dimensión política en el arte. Considerar lo político en el arte no se reduciría entonces a una discusión entre si se trata solo de un asunto de tema o de forma, sino que implica una politización concreta de prácticas artísticas (Brea, 1998), así como una redistribución de lo sensible (Rancière, 2005); lo que conlleva una politización del arte con objetivos políticos claros y no solo para adornar una acción. Considerar lo político en el arte (Richard, 2009) implica hacer parte de la política las herramientas del arte que parecen pertenecer exclusivamente a un mundo cerrado, para cambiar las formas de activismo y hacerlas más potentes.

El arte no es neutral, la pretendida neutralidad que se le ha adjudicado es de por sí una postura ideológica que desvía la mirada y la sujeta a problemas estéticos reducidos en la tendencia del arte por el arte, implantando una separación entre el/la artista, el medio social y los procesos que implica la producción; de esta manera se pretende delimitar el quehacer del arte y en esa medida su percepción y función. En este sentido, podríamos considerar como ejemplo lo acontecido con la pintora colombiana Débora Arango (1907-2005) quien además de pintar desnudos inquietantes desnudó la sociedad de su época y continuó con su trabajo a pesar del ambiente hostil en el que su obra fue encerrada. Débora desafió el "buen gusto" con el que se relaciona aún el arte como entretenimiento elitista, y es que a ella no la emocionaba quedarse en lo onírico o pintar simplemente lo que la rodeaba, no la inspiraba aunque era el contexto que le permitía tener las condiciones necesarias para desarrollar su propuesta; no le interesaba con su obra reproducir su propio mundo, su cotidianidad, sino otras experiencias de las que no hacía parte directamente pero la motivaban a pintar, aunque no necesariamente lo vivía sí lo sentía, era sensible a todo lo que veía y esto era muy diferente a lo que se consideraba como bello, deseable, correcto, digno de pintar, más aún por una mujer ${ }^{1}$.

Por el contrario, para superar esta pretendida neutralidad, se trata de comprender cómo se apropian, renuevan, reinventan, resignifican determinadas prácticas artísticas en su estrecha relación con la acción política, creando tanto nuevas formas de actuar político como propuestas artísticas. Ello que no se restringe solamente a ver la apropiación de una expresión artística o la dimensión estética de una protesta, ya que en este caso la politización de la estética, la potencia política del arte, se reduciría a una estetización de la política 
(Delgado, 2013). Para que esto sea posible se ha propuesto reconocer las posibilidades que tiene el arte en la vida cotidiana, potenciando espacios y expresiones habitualmente no relacionadas con éste; resaltando que debe responder a los contextos sociales y los públicos que están en constante transformación.

En estas propuestas el espacio público, considerado como el escenario de la política por excelencia, va a ser redimensionado. Allí lo participativo, lo colectivo, va a ser central en la medida en que puede representar más que un discurso una apuesta política por la participación democrática directa que supere los límites de los mecanismos formales establecidos en las democracias representativas, así como los lenguajes instaurados para ello ${ }^{2}$. En relación a los espacios para la acción política feminista, la colectiva Féminas Festivas ${ }^{3}$ nos propone reconocer que los espacios tienen implicaciones diferentes con las cuales entran en diálogo las acciones, lo importante es que sean accesibles y se puedan disfrutar. En este sentido la calle es un espacio importante porque no se necesitan muchos recursos, se generan relaciones directas y la participación no es cerrada.

Las acciones políticas feministas son diferentes según los espacios donde tengan lugar, en concordancia con lo que se quiera movilizar y propiciar el lugar es importante -como el atrio de una iglesia cuando el tema de la acción es el derecho al aborto-; además, la relevancia aumenta cuando la intención es controvertir los espacios que han sido institucionalizados para el ejercicio de la política desde una mirada tradicional. Para este cuestionamiento la calle es algo que los grupos se han tomado, es importante como apuesta política al ser un espacio negado a las mujeres o que es necesario resignificar, como cuando las acciones se reapropian de la noche. Los espacios públicos y abiertos también son relevantes cuando la intención es salir de los formalismos del mundo del arte, para dar a conocer otras miradas sobre el mundo. En este sentido, es importante que el arte esté en la calle, que la gente tenga acceso fuera de los lugares institucionales que pueden ser incómodos. La calle hace parte justamente de la apuesta de la batucada feminista La Tremenda Revoltosa para sacar las discusiones políticas de espacios privilegiados y seguros -como pueden ser los

2 Para este y otros análisis que propongo en adelante retomaré algunos aspectos de acciones políticas feministas que devienen de mi experiencia de trabajo con colectivas de activistas, grupos artísticos y artistas posicionadas como feministas en Colombia. Cada una de estas propuestas implican una reflexión más amplia, sin embargo a manera de ejemplo de lo que analizo en este artículo narraré algunos aspectos de sus activismos artísticos feministas.

3 Féminas Festivas es una colectiva feminista de la ciudad de Cali - Colombia que apuesta por la creación artística y comunicativa con la cual abordan diferentes temas como militarismo, ecología, violencias contra las mujeres, feminismos, derechos, aborto, paz, la colonización, el capitalismo, entre otros. Con su apuesta de activismo feminista que denominan como "experimentos chamánicos-políticos-poéticos" intervienen en la calle, en las escuelas, en las fiestas, en las manifestaciones, donde quieran. Féminas Festivas ha explorado las campañas gráficas, el performance, la vídeo instalación, el teatro de sombras, la radio experimental, el audiovisual, la curaduría musical, la fotografía, el discurso televisivo, los fanzines, la traducción de discurso académico y la elaboración teórica. Su acción es ecléctica creando un activismo festivo que es potente al manejar diferentes materiales y medios con los que proponen juegos donde se junta el arte con la comunicación. Ver más en: https://feminasfestivas.hotglue.me 
de la Universidad-; una manera de materializar también sus ideas feministas, de hacerlas acción ocupando las calles, convirtiéndolas en el lugar de la política feminista. La calle es el escenario donde gozan su activismo con una apuesta clara por renovar las formas de hacer política feminista en Colombia; desde allí las activistas de La Tremenda Revoltosa ${ }^{4}$ saben que cuando avivan el discurso feminista a través de los tambores esto hace que llegue a otras personas, las atrae y las interpela de otras maneras. Para ellas el arte no es solo forma, ni la música la parte divertida y recreativa que anima una manifestación política, por ello con la batucada buscan revertir ese lugar que el arte tiene en la política para hacer de éste la acción y la construcción política misma en lo público.

Vemos entonces como las expresiones artísticas más que un medio van a ser la forma de hacer política, una política otra que se posiciona de manera crítica frente a diversos problemas sociales. Según lo que se quiera denunciar, los espacios de circulación de las propuestas y el tiempo para producirlas se elegirá el medio. Todas las expresiones artísticas son medios propicios para la acción política; las razones por las cuales son escogidas tienen que ver principalmente con los recursos, el lugar, a quién va dirigido, el tiempo y las condiciones para la producción. Se comprende que cada una tiene manifestaciones diferentes que se pueden potenciar, aunque las que contemplan la palabra tendrían una ventaja. Es en este sentido que se concreta la potencia política del arte al reinventar las expresiones artísticas para reflexionar sobre lo cotidiano, desnaturalizar aspectos de la vida normalizados que, por el contrario, son productos de relaciones de poder y expresión de desigualdades y discriminaciones; además de presentar y representar otras miradas de diversos aspectos sobre los cuales impera una visión hegemónica y así movilizar diferentes voces y puntos de vista.

En relación a estas apuestas el arte feminista fue uno de los pioneros. Según Helena Reckitt (2005) el feminismo ha redefinido los términos del arte de finales del siglo XX, relevando presunciones culturales sobre el género, politizando el vínculo entre lo público y lo privado, así como explorando lo propio de la diferencia sexual, además del énfasis de la especificidad de los cuerpos que no solo está marcada por el género sino también por la raza, la edad y la clase social; todo ello producto de las respuestas que las artistas han dado a los feminismos, en su estrecha relación con las demandas políticas y los debates del pensamiento feminista. Un ejemplo de ello es el trabajo de la artista feminista

\footnotetext{
4 La Tremenda Revoltosa lucha con los tambores de manera autónoma y autogestionaria contra el racismo, el heterosexismo normativo, el capitalismo, el militarismo y otras formas de opresión y violencia, desde Bogotá - Colombia. Esta batucada feminista también con consignas, comunicados, intervenciones públicas, manifestaciones, propone una mirada feminista crítica frente a los diversos problemas sociales, económicos, políticos que afectan a la sociedad colombiana. Se articulan con otros movimientos sociales, construyendo un feminismo que no es "efímero, es trascendente desde lo mas íntimo, individual, corporal, hasta lo más colectivo". Ver más sobre la acción política artística feminista de La Tremenda Revoltosa en: https://www.youtube.com/watch?v=7OKkbRM7TDc
} 
Colombiana Ana María Villate Marín ${ }^{5}$. El performance con el que comienza su camino como artista feminista es “Vanidosa?”, en éste la artista en una mesa dispuesta para cenar como cualquier otra se come las páginas de la revista Vanidades, una publicación representativa de las denominadas revistas femeninas donde los estereotipos y las constricciones de género son evidentes. Es de resaltar de las prácticas artísticas de la artista la importancia que le da a su postura política como parte esencial de su propuesta estética, sin hacer diferencia entre forma y contenido. Aunque algunas de sus prácticas puedan no ser reconocidas como artísticas en los estrechos límites del mundo del arte, para ella también tienen validez como propuestas artísticas, como lugares de enunciación activistas desde los cuales poner en discusión los discursos y prácticas que hacen parte del mundo del arte.

Es así como el arte feminista, como otras experiencias de arte con política, van a mostrar la importancia de la postura de la o el artista que se piensa y actúa también como activista; ya que, aunque el rol de la o el artista sigue siendo central, las modificaciones que traen a las prácticas artísticas estas apuestas tienen implicaciones también en la idea de quién o quienes pueden hacer arte, con qué fines y al servicio de qué y para quién. De allí surgen diversas experiencias en la apropiación que se hace del arte fuera del canon, que se han denominado como "estéticas de la resistencia" y "estéticas alternativas", con las cuales se procura cambiar ciertas pautas culturales y sociales, así como transformar la producción artística y su recepción.

Hal Foster (2001) sugiere que al reconocerse lo cultural como un lugar de contestación, la cultura como un lugar de conflicto, la estrategia a seguir es la resistencia como práctica que exceda las pretensiones del capital, con el fin de enfrentar la capacidad que éste tiene de beneficiarse y descodificar lo que se constituye en su contra -tal es el caso de la contracultura-. De allí que el autor abogue por proyectos de posición contrahegemónica y de resistencia “con el fin de no ver la sociedad como "un sistema total", sino como una coyuntura de prácticas, muchas de ellas contrapuestas, en donde lo cultural es una arena donde es posible la contestación [...] solo será en estos términos -en tanto práctica de resistencia o interferencia- como se puede concebir lo político en el arte" (Foster, 2001:106). Asimismo, el autor afirma que las prácticas de resistencia que son posibles deben superar la idea central de las propuestas contraculturales que solo se preocupan por apoderarse de los medios ignorando la dominación que está inscrita en sus propias formas, a las cuales es difícil de responder estructuralmente.

5 Con sus propuestas artísticas Ana María Villate se posiciona críticamente frente a los estereotipos de género dominantes en la publicidad, el deber ser de la feminidad impuesta, la performatividad del género, así como la situación política del país, el poder, el racismo, el colonialismo; por medio de performances, video arte, dibujo, pintura y escultura con los cuales ha participado en diversas iniciativas colectivas y exposiciones desde el 2003. Algunas obras de la artista están disponibles en: http://anamariavillate.laveneno.org/ 
Se trata por tanto no solo de la reapropiación sino de la resignificación que del arte pueden hacer las personas y los colectivos que han sido subalternizados, racializados, excluidos, víctimas de violencias, etc., quienes también encuentran en el arte otras formas de denunciar y expresar no solo los disentimientos sino las propuestas. El arte por tanto tiene la posibilidad de ser potencializado para diversos fines, con lo que cada expresión artística podría aportar según los objetivos propuestos. También como forma de resistencia y respuesta representa una oportunidad para los colectivos a los que les es negado el acceso a los espacios institucionales de la política o que ya no los encuentran legítimos. Se trata entonces de la puesta en práctica de una noción más amplia de la política que no solo tiene que ver con los espacios formales de las democracias representativas, sino con el ejercicio cotidiano, la politización de diversos aspectos de la vida, la política como conjunto de relaciones donde también tienen lugar los afectos, las sensibilidades, los anhelos por mundos mejores.

En este sentido, continuando con los ejemplos situados en Colombia y la importancia para pensar el arte feminista de tener en cuenta las distintas geografías del feminismo (Pollock, 1996), podemos resaltar como el grupo de punk feminista Polikarpa y su Viciosas ${ }^{6}$ no solo participa activamente en las luchas del movimiento de mujeres y feminista en el país en sus movilizaciones y campañas, sino que concibe sus conciertos como acciones políticas. Para ellas el concierto de punk es una manera de discurso y movilización política, haciendo que la relación entre arte y política sea directa porque hacen música pero pensada con un fin político fuerte. Un ejemplo de ello fue su concierto en el festival Antimili sonoro del 2015, donde en diferentes momentos del concierto subieron al escenario dos mujeres del grupo que se conoce en el país como "Las Madres de Soacha”, quienes vienen luchando por verdad, justicia y reparación en el asesinato de sus hijos por parte del Estado colombiano, conocidos como falsos positivos ${ }^{7}$.

6 Con un recorrido de más de diez años en la escena Polikarpa y sus Viciosas es una de las primeras bandas de punk compuesta solo por mujeres en Colombia, con su música en diferentes espacios de activismo denuncian la situación de las mujeres y del país desde una postura anarco-punk feminista. Como banda cuentan con un reconocimiento en la escena punk, incluso a nivel internacional, que las ha convertido en un referente para que otras mujeres se animaran a tener sus propias bandas transformando esta escena marcada fuertemente por la presencia masculina.

7 Las Madres de Soacha hoy en día son actoras políticas importantes en la lucha de las mujeres que en Colombia trabajan por el reconocimiento de las formas como la guerra las ha afectado por su condición y posición de género. Los falsos positivos "Son hechos que se configuran como acciones tendientes a demostrar los resultados de una creciente política de seguridad desplegada por la Fuerza Pública. Dichas acciones se desarrollan en virtud de un premio o una bonificación por productividad para los miembros del ejército, pero en realidad son acciones que encajan en las llamadas ejecuciones extrajudiciales. En Colombia se han presentado más de tres mil falsos positivos, los primeros casos se descubrieron en Ocaña, Santander, eran jóvenes de estratos populares provenientes de Soacha, Cundinamarca, de donde fueron sacados con engaños; luego aparecerían como guerrilleros dados de baja en combate. Hoy sus madres reclaman justicia” (Díaz, et. al., 2012). Ver esta acción en: https://www.youtube.com/ watch?v=nx8c_fQOMV0 
Igualmente, es necesario que podamos comprender la relación del arte con lo social no solo términos de las maneras como éste la determina, sino el rol que el arte puede tener justamente en su transformación. Así las propuestas de las prácticas artísticas no solo simbolizarían lo que constituye la vida social sino que tienen la posibilidad de re-simbolizarlo, es decir, no es un mero reflejo de la realidad ya que entran a mediar los lenguajes artísticos -sean estos plásticos, musicales, literarios, cinematográficos, performativos, etc.- y las diversas formas como éstos se han construido y son aprehendidos históricamente, en relación con los contextos en los que tienen lugar. Por tanto, no se trata solo de una crítica de la representación dominante, sino de la representación misma como proceso, práctica que consiste en mostrar como las representaciones de la realidad son parciales y están ideológicamente definidas expresando relaciones de poder.

Para que esto sea posible y se resignifique la potencialidad política del arte, éste ha extendido su acción más allá del campo artístico, incrementando a las prácticas artísticas basadas en objetos otras prácticas donde van a ser fundamentales los contextos; por eso el uso de los medios de comunicación, los espacios urbanos, las redes digitales, así como diversos espacios de participación social, nuevas disposiciones del arte que sobrepasan la dicotomía encerramiento-transgresión. Así la superación de barreras que trascienden lo artístico posibilitan una reflexión sobre el estado del mundo (Canclini, 2010).

De allí que esta acción política tenga lugar en espacios susceptibles de ser analizados con más profundidad, sobre los cuales se busca incidir creando procesos artísticos que piensen e influyan en lo concreto, lo inmediato, lo transformable. Así se explora la potencia política del arte para la movilización de alternativas y propuestas políticas, donde se conjuguen lo silenciado y sujetado al olvido, lo descalificado y subvalorado, y lo que aún está por construir para poder resistir a la cultura hegemónica que nos arrebata el arte de la manos. Desde un lugar que puede ser común como el teatro, por ejemplo, el grupo La Máscara ${ }^{8}$ de la ciudad de Cali ha logrado consolidar en sus 46 años de trabajo una dramaturgia propia articulada con una posición política. Su trabajo

8 Este grupo abrió el caminó en Colombia para cambiar el lugar de las mujeres en el teatro. De la actuación en otros grupos de teatro mixtos pasaron a ser protagonistas, directoras, creadoras, escritoras, haciendo dramaturgias atrevidas y montajes propios en torno a temas que no eran abordados comúnmente en el teatro como el aborto, la prostitución, la violencia contra las mujeres, entre otros; reconociendo y dando importancia política a problemas relacionados con las mujeres que se atrevieron a llevar a los escenarios y a las calles por primera vez en el país. Como pioneras del teatro de género y feminista en Colombia desde 1972 hasta el día de hoy han construido con su propuesta teatral una mirada estética y crítica frente a la situación de las mujeres en el país y en el mundo, consolidando un lenguaje singular con el cual pasan de ser víctimas o temas secundarios en el teatro a protagonistas de montajes, con miradas propias desde una perspectiva feminista, en creación constante de diferentes propuestas con las cuales ponen en práctica otras formas de quehacer teatral feminista. Asimismo, lideran espacios de formación en dramaturgia feminista y trabajos comunitarios en la búsqueda de construcción de alternativas de vida para mujeres, jóvenes, niñas y niños de sectores empobrecidos de la ciudad a partir de las diversas herramientas del teatro. Ver más en: http://teatrolamascara.com/ 
artístico político demuestra que es posible poner en escena reivindicaciones de los feminismos, con propuestas estéticas innovadoras que permiten que se piense sobre diferentes temas y problemas de otras maneras, llegando a la gente con otros lenguajes. Así se fortalece la posibilidad que tienen las artes de ver otros mundos posibles, cuestionar la verdad, lo que creemos que es natural. Con el poder comunicativo del teatro, que no esta sólo en la palabra sino en el cuerpo, los gestos, la música, todo lo que compone la dramaturgia, como espectadora te puedes identificar o puedes rechazar lo que ves en el escenario, lo que genera una relación con el público que es privilegiada; para La Máscara si esto se hace desde asuntos más profundos, es posible generar y movilizar más cosas y así propiciar una conciencia política en medio de un campo donde el teatro político, comprometido, hoy en día es marginal.

\section{Activismo artístico feminista}

El activismo feminista, más ampliamente la política feminista, es un eje fundamental del análisis para comprender la relación entre teoría y práctica en el movimiento feminista, y las implicaciones en ejercicios concretos de la política. En este artículo he referido, a partir de los ejemplos situados en Colombia, que existen otras formas de acción política feminista que otorgan centralidad al arte, para las cuales es importante comprender las artes feministas como prácticas políticas con sus propios repertorios. En este sentido, se trata de repensar las interrelaciones entre la acción política, la práctica artística, el activismo feminista desde el arte y los aportes del arte feminista; para comprender las potencialidades políticas de las expresiones artísticas en estos activismos que reinventan la política, el arte y sus relaciones. Además, considero importante hacer visibles otras políticas feministas que también constituyen el movimiento feminista; aunque partimos del hecho que existen diferentes expresiones, es necesario reconocerlas para dar valor político a los diferentes activismos ya que esto permite ampliar los repertorios de acción política, así como los diversos significados del ser feminista y la apertura de espacios para su expresión.

Los feminismos como movimientos políticos han tenido una amplia repercusión tanto sobre el arte activista como sobre el que se posiciona como feminista, inicialmente hecho por mujeres y que hoy en día se extiende a diversos sujetos que también se reivindican como artistas feministas; creando un tipo de arte subversivo que recupera, retoma los espacios negados a las mujeres y a quienes cuestionan el género abordando críticamente el problema de la autorepresentación. El activismo feminista con todas sus estrategias, así como las teorías feministas, van a constituirse por tanto en fuentes importantes para el trabajo de las artistas que se posicionan como feministas, estrechando la relación entre pensamiento feminista y creación artística. Nina Felshin (2001: 83) afirma que los temas feministas y de género han alimentado la producción 
del arte activista de un modo predominante, haciendo un uso creativo de las metodologías feministas para la toma de conciencia del propio poder y la identidad comunitaria, proporcionado importantes precedentes para el activismo contemporáneo.

Por su parte, Silvia Gil (2011: 364) nos recuerda como desde los años noventa las prácticas artísticas van adquiriendo un rol importante en la política y para los feminismos, en un contexto en el que la esfera cultural adquiere mayor importancia. Dichas prácticas van a ser la manera como se problematiza la realidad, más allá del uso clásico del arte político como medio de propaganda. En Latinoamérica, según el análisis de Julia Antivilo (2015: 180-181), la protesta creativa enlaza el arte activista con la historia de la acción política del movimiento feminista. La autora reconoce que en este camino no siempre han participado las artistas junto con el movimiento; sin embargo, las protestas feministas se han destacado por la creatividad para expresar sus demandas. A pesar de este signo presente en el activismo feminista, no todas las activistas reconocen ser artistas en sus protestas creativas o acciones que, como expresa la autora, detentan una política estética. Ello no impide reconocer que, en el marco de la acción política feminista, en Latinoamérica han existido constantes muestras definidas desde el arte activista.

De sus inicios las artes feministas tuvieron que enfrentar directamente el canon artístico ya que, al igual que en otros espacios de la vida social, éste se ha consolidado bajo premisas estrechamente patriarcales, androcéntricas y sexistas. La denuncia de dichas premisas que prevalecen en la ideología y las prácticas artísticas, es realizada por las artistas feministas reivindicando otras formas no canónicas de hacer arte en contenido, forma e intención política; realizando un vehemente y controvertido trabajo, en la medida en que develan las prácticas sociales que sostienen y legitiman el lugar de las mujeres en el arte y la mirada sobre su trabajo artístico. Pero no se queda solo allí, pues también van a ser agudas en la crítica a las condiciones históricas, sociales, políticas, económicas del arte y su canon; así como al campo de la cultura, sus prácticas legitimadas de acceso, producción, circulación y recepción, con todo lo que ello ha implicado para las mujeres.

Además, las artes feministas, como afirma Griselda Pollock (2001, 1994), han realizado aportes relacionados con las formas como han entrado tanto en relación como en discusión con el canon del arte deshaciendo sus pilares, consolidando otras posturas y maneras de ver y leer las prácticas artísticas, definiendo que se hace necesario construir otra historia y teoría del arte. Por todo ello, el arte feminista incide y confronta no solo al arte como institución supuestamente universal y neutral, sino a la sociedad misma configurada desde un orden patriarcal, cuestionando los presupuestos de la cultura dominante. De allí su importancia para la acción política y el hecho que las propuestas de las artistas feministas reflejen la necesidad de un arte comprometido con 
la transformación social. Ello permite repensar la función social del arte y su sentido, la manera como las acciones políticas artísticas pueden reinventar la acción política, cómo las prácticas artísticas, en general el arte y la cultura pueden ser caminos de transformaciones sociales.

En la búsqueda de repertorios y lugares de enunciación para concretar estas propuestas, el cuerpo se ha constituido en un instrumento político y epistemológico central para los feminismos, debido a sus implicaciones identitarias, teóricas y políticas (Esteban, 2011: 47). Esto conlleva a que iniciativas y acciones feministas que se hacen desde el cuerpo, como las de las acciones artísticas, sean un lugar privilegiado para la resistencia. Tanto el movimiento como las artistas feministas desde sus inicios comprendieron que el cuerpo, al ser uno de los lugares donde se inscriben las relaciones de poder, puede ser al mismo tiempo fuente de subversiones. En este sentido, si comprendemos el cuerpo como campo político, que puede ser tanto disciplinado como subvertido, implica que el cuerpo de las mujeres puede convertirse en un cuerpo sujeto. Desde esta perspectiva, las artes feministas que pintan, esculpen, fotografían o transforman ese cuerpo sujeto de las mujeres, pueden ser comprendidas como acciones políticas estéticas. Dichas acciones son parte de las diversas estrategias críticas que hacen de las artes feministas espacios políticos (Antivilo, 2015: 39-40).

Cuando el cuerpo es un tema central y no solo un tema, sino que se convierte en sujeto, como lo han hecho las artes feministas, el performance se constituye en una plataforma importante, en un leguaje propicio para la acción política feminista. En este sentido, Del Río y Muñoz (2003:32) afirman que las características que se desprendieron de las acciones feministas desde las décadas de los 60 y 70 han continuado definiendo gran parte del arte de acción -cuya expresión más difundida es el performance-, que podemos reconocer en su sentido activista, la mirada política capaz de perturbar la norma, las estructuras o la categorización social, cultural y sexual, el cuerpo como contenedor, como escenario donde discurren y se proyectan discursos críticos y prácticas artísticas, la crítica a la representación capaz de forjar nuevos modelos, la conquista del espacio público, etc. En definitiva, las características subversivas de un lenguaje que busca un mayor compromiso con la vida, al implicar el propio cuerpo-espacio en el que se ejerce la opresión como escenario de reflexión y denuncia.

Simultáneamente, esta complicidad del arte con la política ha conllevado la creación de nociones que nos ayuden a entender sus implicaciones y desde donde posicionarse, artivismo es una de ellas. Se usa actualmente para nombrar la relación entre arte y activismo que, a diferencia del activismo artístico ${ }^{9}$,

$9 \mathrm{El}$ activismo artístico hace referencia principalmente a la producción tanto de textos teóricos como obras e intervenciones artísticas, considerada como una práctica artística crítica de las funciones sociales, ideológicas y de representación de las instituciones artísticas; comprendidas como espacios de 
define su campo de acción principalmente en las luchas políticas y no en el mundo del arte; conceptualizado como "a hybrid neologism that signifies work created by individuals who see an organic relationship between art and activism” (Sandoval y Latorre, 2008: 82). Por su parte, Julia Ramírez (2014) quien se ha interesado en investigar movimientos que denomina como utopías artísticas de revuelta ${ }^{10}$, afirma que éstos reflejan la importancia que ha ido adquiriendo para la protesta social la creación de simbolismo que, además de explorar la creatividad plástica con diferentes elementos visuales, trabaja sobre el carácter estético y simbólico de las acciones. Se trata de una reflexión acerca de las posibilidades que ofrece el arte cuando es concebida como una herramienta situada en los escenarios de los conflictos. Estas acciones directas creativas, como las denomina Ramírez, van a ser la base para la creación de nuevas nociones como artivismo ${ }^{11}$.

Sin embargo, sin desconocer la importancia política del artivismo como práctica contrahegemónica, considero que tanto ésta como la noción de activismo artístico, se suscriben en la línea habitual que piensa la relación entre arte y política como forma y contenido, respectivamente. Se trata por el contrario, como propone Nelly Richard (2011: 39), de reconceptualizar el nexo entre arte y política, fuera de los caminos trazados por la subordinación ideológica a los repertorios de la política. Sin dejar de lado estas consideraciones sobre la relación entre arte y activismo, considero que la idea de acción política artística feminista es más amplia y adecuada en la medida en que las artes y las políticas feministas han transformado y transforman tanto el mundo del arte como el de la política en sus ideas canónicas y limitantes; con lo cual se supera la subordinación de las formas a los contenidos y su ejercicio meramente utilitario, porque el propio medio se convierte en el acción política. En todo ello el arte va adquiriendo un lugar significativo en las políticas feministas, frente a lo cual considero importante diferenciar la apropiación de algunas herramientas de determinadas expresiones artísticas para acciones puntuales, de la apuesta por el arte como acción política feminista ${ }^{12}$.

circunscripción factibles de ser atacados estética, política y teóricamente cuando la institución artística se plantea como un problema para los y las artistas.

10 Movimientos que desde los años 90 han removido la acción política en Europa, particularmente Claremont Road, Reclaim the Streets y la Ciudad del Sol. Para la autora estos movimientos hacen parte de una impetuosa innovación de las formas de protesta que analiza como una especie de giro cultural de la política no institucionalizada que deviene de los movimientos sociales de los años 60 .

11 Por su parte, en la reflexión que Chantal Mouffe hace del activismo artístico en el espacio agonista, va a hacer uso del término prácticas artivistas para afirmar la importancia de que las formas artísticas se pongan "al servicio del activismo político". Para la autora este hecho representa una dimensión importante de la política radical, ya que estas prácticas pueden ser comprendidas como "acciones contrahegemónicas en relación a la apropiación capitalista de la estética y su objetivo de asegurar y expandir el proceso de valorización” (Mouffe, 2014: 105).

12Muestra de ello son las experiencias aquí referidas de acción política de Féminas Féstivas, La Tremenda Revoltosa, Ana María Villate, La Máscara y Polikarpa y sus Viciosas, quienes reconocen su interés por hacer de los discursos feministas algo comprensible, cotidiano, concretándolo con otros lenguajes como los artísticos. Sus repertorios de acción son diversos, según sus recursos e intereses 
De esta manera será posible pensar y practicar los feminismos desde todos los lugares, donde lo personal como político se convierte en una práctica que tiene un lugar significativo en la construcción de las propuestas. Así se concreta la política feminista desde lo más intimo, desde el propio cuerpo, dando valor político a lo que no es considerado como tal en otros espacios; con lo cual se van construyendo posiciones como sujetas políticas, donde la acción política significa propuestas de transformación, con formas de pensar y actuar con las cuales se cambia no solo el entorno sino a si mismas. Para quienes tienen ideas tradicionales del arte y de la política propuestas de activismo artístico feminista pueden no ser ni lo uno ni lo otro, sin embargo, cuando se conjuga el arte y la política desde una perspectiva feminista se construye otra relación entre éstas y se hace otro camino.

En este devenir, además de la teoría feminista, ha sido importante la experiencia, cómo comunicar, mostrar, poner en discusión lo que pensamos y proponemos, es allí donde entran los aportes de las artistas que junto con las activistas van tejiendo entre movimiento, activismo, teoría y práctica artística. Esto implica reconocer las artes feministas como otras formas de hacer política feminista, como otros activismos que hacen posible tocar, pintar, cantar, gritar, performancear ${ }^{13}$ los feminismos; construidos en la acción de un hacer política feminista que además será agradable, gozosa, divertida, festiva ${ }^{14}$. De esta manera se enfrenta el desgaste de las formas de la política tradicional y se libera el arte de los espacios creados oficialmente para su difusión, haciendo de ésta una práctica al alcance de todas y todos.

En síntesis, la acción política artística feminista procura superar las formas tradicionales de hacer política y de hacer arte desde el feminismo para volverlas más pertinentes y contundentes, con el fin de generar conocimientos, preguntas, denuncias, resistencias, etc. Estas acciones apropian y reinventan determinadas prácticas artísticas en su estrecha relación con la acción política, creando tanto nuevas formas de actuar político como propuestas artísticas; haciendo de ello ejercicios concretos de renovación de la política que posibilita el arte cuando abre y hace accesibles otros lugares y lenguajes. La acción política artística feminista reinventa, resignifica el vínculo entre arte y política desde un anclaje que es justamente el que potencia los lenguajes artísticos para poner en ellos otros discursos desde posturas feministas críticas, que tienen en cuenta las implicaciones

donde se mueven entre la guerrillería (Féminas Festivas inventan esta palabra para denominar su apuesta por dinamitar, pero no con explosivos, sino con otras "armas" que son sus preferidas como la ironía, la burla, lo carnavalesco) y el activismo festivo, la dramaturgia feminista, el trabajo comunitario, la música y la reivindicación de la alegría como resistencia.

13 "Performancear es la literalidad del verbo que significa devenir, que dice haciendo, piensa y hace desde una trascendencia de sus actos, que pueden tener algo terapéutico no sólo para quien realiza la acción, sino también para quien la presencia" (Antivilo, 2015: 150).

14 Todas estas propuestas pueden ser impulsadas por activistas que sin necesidad de contar con una formación profesional en el campo artístico hacen arte, aprendiendo en el propio quehacer de las apuestas colectivas donde acceden a diferentes lenguajes artísticos para potenciarlos y posicionarlos en diferentes escenarios políticos. 
y compromisos políticos de estas apuestas de activismo con otros lenguajes más accesibles donde el arte es politizado para denunciar, comunicar y resistir. De esta manera se concretan otras políticas feministas que serán diversas, colectivas, artísticas, corporizadas; en respuesta a la necesidad de que los feminismos construyan políticamente desde otros lenguajes, como los artísticos, apostando por repertorios de acción política diferentes a los usados tradicionalmente y reconociendo otras prácticas y conocimientos feministas que no son sólo los de la academia -aunque también comuniquen reflexiones feministas elaboradas en ésta-. Así se refuerza lo estético para expresar inconformidades y otras miradas sobre la realidad que, aunque no transforme directamente la sociedad, sí denuncia, cuestiona y rompe el silencio, haciendo factibles otras propuestas que cambian no solo el lugar del arte en nuestra sociedad sino en la política.

\section{Referências bibliográficas}

ÁLVAREZ, Sonia, DAGNINO, Evelina, ESCOBAR, Arturo (org.) (2000), Cultura e politica nos movimentos sociais latino-americanos, Belo Horizonte, Ed. UFMG.

ANTIVILO, Julia (2015), Entre lo sagrado y lo profano se tejen rebeldias. Arte feminista Latinoamericano, Bogotá, Ediciones desde abajo.

BREA, José Luis (1998), "Políticas del Arte (s. 21)", Acción Paralela, No. 4., 1-18 [Online], disponível em: http://www.accpar.org/ numero4/politicas.htm [consultado em: 14 de enero de 2015].

CANCLINI, Nestor García (2010), La sociedad sin relato. Antropología y estética de la inminencia, Buenos Aires, Kats editores.

CASTAÑEDA, Griselda (2002), "El ejercicio de la ciudadanía de las mujeres y su contribución a la democracia”, Debate Feminista, vol. 23 (año 12), 125-137.

DEL RÍO, Alfonso y MUÑOZ, Cintas V. (2013), "Los discursos feministas y las acciones de mujeres en la configuración del lenguaje de la performance”, Arte y Movimiento, No 8, 21-32.

DELGADO, Ricardo (2007), "Los marcos de acción colectiva y sus implicaciones culturales en la construcción de ciudadanía”, Universitas humanística, no. 64, 41-66.

DELGADO, Manuel (2013), “Artivismo y pospolítica. Sobre la estetización de las luchas sociales en contextos urbanos", Institut Català d Antropologia QuAderns-e, no. 18 (2), 68-80.

ESCOBAR, Arturo (et. al.) (eds.) (2001), Política cultural \& cultura política: una mirada sobre los movimientos sociales latinoamericanos, Bogotá, Taurus.

ESTEBAN, Mari Luz (2011), “Cuerpo y políticas feministas: el feminismo como cuerpo" in Nacho Álvarez, y Cristina Villalba (Coords.), Cuerpos politicos y agencia. Reflexiones feministas sobre cuerpo, trabajo y colonialidad, Granada, Universidad de Granada, 45-84.

FELSHIN, Nina (2001), “¿Pero esto es arte? El espíritu del arte como activismo”, in Paloma Blanco y Jesús Carrillo (et. al.), Modos de hacer. Arte crítico, esfera pública y acción directa, Salamanca, Universidad de Salamanca,73-94.

FOSTER, Hal (2001), "Recodificaciones: hacia una noción de lo político en el arte contemporáneo", in Paloma Blanco, y Jesús Carrillo (et. al.), Modos de hacer. Arte crítico, esfera pública y acción directa, Salamanca, Universidad de Salamanca, 95- 126.

FRASER, Nancy (1992), "Repensando la esfera pública: una contribución a la crítica de la democracia actualmente existente", Debate Feminista, vol. 7 (año 4), México D.F, 23-58.

GIL, Silvia L. (2011), Nuevos feminismos. Sentidos comunes en la dispersión: una historia de trayectorias y rupturas en el Estado español, Madrid: Traficantes de Sueños. 
IBARRA, Pedro y CORTINA, Mercè. (Comps.) (2011), Recuperando la radicalidad. Un encuentro en torno al análisis político crítico, Barcelona, hacer Editorial.

MACCIONI, Laura (2002), "Valoración de la democracia y resignificación de "política” y "cultura”: Sobre las políticas culturales como metapolíticas”, in Daniel Mato (Coord.), Estudios y Otras Prácticas Intelectuales Latinoamericanas en Cultura y Poder, Caracas, CLACSO, CEAP, FACES, Universidad Central de Venezuela, 189-200.

MOUFFE, Chantal (1999), El retorno de lo político. Comunidad, ciudadanía, pluralismo, democracia radical, Barcelona, Paidós.

MOUFFE, Chantal (2007), “Artistic activism and agonistic spaces”, Art \& Research, Vol.1 (No. 2), 1-5.

MOUFFE, Chantal (2014), Agonística: pensar el mundo políticamente, Buenos Aires, Fondo de Cultura Económica.

POLLOCK, Griselda (1994), "Puede la historia del arte sobrevivir al feminismo" in Yves Michaud (ed). Feminisme, art et histoire de l'art. Paris: Ecole nationale supérieure des Beaux-Arts, disponível em http:// www.estudiosonline.net/texts/pollock.htm [consultado em: 30 de diciembre de 2013].

POLLOCK, Griselda (1996), Generations and Geographies in the Visual Arts: Feminist Readings, Nueva York y Londres, Routledge.

POLLOCK, Griselda (2001), "Diferenciando: el encuentro del feminismo con el canon”, in Karen Cordero e Inda Sáenz (comp.), Crítica feminista en la teoría e historia del arte, México, Universidad Iberoamericana - PUEG, 241-160.

RAMÍREZ, Julia (2014), Utopías artísticas de revuelta. Claremont Road, Reclaim the Streets, la Ciudad del Sol, Madrid, Cátedra.

RANCIÈRE, Jacques (2005), Sobre politicas estéticas, Barcelona, Universidad Autónoma de Barcelona.

RECKITT, Helena (ed.) (2005), Arte y feminismo, Nueva York y Londres, Phaidon.

RICHARD, Nelly (2009), “Lo político en el arte: arte, política e instituciones”, E-misférica, Disponível em: http://hemi.nyu.edu/hemi/en/e-misferica-62/richard [consultado em: 3 de junio de 2013].

RICHARD, Nelly (2011), Lo político y lo crítico en el arte, Valencia, Institut Valencià d'Art.

RODRÍGUEZ, Emanuel (2012), "Retos y encrucijadas conceptuales del estudio de la política como sistema cultural”, Andamios, vol. 9 (no 18), 263-291.

SANDOVAL, Chela; LATORRE, Guisela (2008), "Chicana/o Artivism: Judy Baca's Digital Work with Youth of Color" in Anna Everett (ed.) Learning Race and Ethnicity: Youth and Digital Media, Cambridge, MA: The MIT Press, 81-108 [online], Disponível em: http:// www.issuelab.org/resources/826/826.pdf [consultado em: 21 de noviembre de 2013].

SLATER, David (2000), "Repensando as espacialidades dos movimentos sociais. Questões de fronteiras, cultura e política em tempos globais", in Sonia Álvarez, Evelina Dagnino y Arturo Escobar (org.), Cultura e política nos movimentos sociais latino-americanos, Belo Horizonte, Ed. UFMG, 503-533.

TARRÉS, María Luisa (2002), "Para un debate sobre la política y el género en América Latina", Debate feminista, vol. 26 (año 13), México D.F, 119-139.

YOUNG, Iris Marion (1990), "Imparcialidad y lo cívico público. Algunas implicaciones de las críticas feministas a la teoría moral y política”, in Seyla Behabid y Drucilla Cornella (Eds.), Teoría feminista y teoría crítica. Ensayos sobre la política de género en las sociedades del capitalismo tardio, Valencia, Edicions Afons El Magnàmin, 89-117. 